\title{
Um estatuto para a poesia infantil contemporânea: reflexões a partir do PNBE
}

\author{
Marli Cristina Tasca Marangoni ${ }^{1}$ \\ Flávia Brocchetto Ramos ${ }^{2}$
}

\begin{abstract}
Nosso conhecimento não era de estudar em livros.
Era de pegar de apalpar de ouvir e de outros sentidos.

Seria um saber primordial?

Nossas palavras se ajuntavam uma na outra por amor e não por sintaxe.

A gente queria o arpejo. O canto. O gorjeio das palavras.
\end{abstract}

Manoel de Barros

Os saberes do leitor criança estão ligados aos sentidos do corpo, ao que é concreto e sensível. Não se constituem por conteúdos livrescos, mas pautam-se em construções anteriores ao processo de escolarização, enraizadas no mundo, na observação da natureza, na experiência. Em sua relação inaugural com a linguagem, a criança toma a palavra como uma matéria feita de sons, cuja relação com os signos artificiais da escrita não está convencionada. No exercício de leis de combinação, atração e repulsa, que a gramática não rege, a atuação do ser infantil se liga à materialidade musical das palavras.

Para o sujeito infantil, a experiência poética coincide com a apreensão do universo, pois ele lê poeticamente seu entorno, de modo espontâneo e talvez inconsciente, ainda que não conheça, necessariamente, as letras. A despeito de a infância ter-se transformado tanto e continuamente, importa perguntar como se tem oferecido a poesia que se lê em letras, nos livros, a esse ser infantil, que vive a poesia do mundo.

A poesia infantil no Brasil surge com a obra Flores do campo: poesias infantis, de José Fialho Dutra, em 1882. No livro, não há preocupação formal ou temática com o leitor mirim, predominando tom doutrinário que incentiva, por exemplo, o amor ao diretor do colégio. À obra de Fialho Dutra, segue-se o Livro das crianças, de Zalina Rolin (editado pelo governo paulista em 1897), constituído por trinta poemas elaborados a

\footnotetext{
${ }^{1}$ Doutora em letras e professora da Faculdade CNEC Farroupilha, Farroupilha, RS, Brasil. E-mail: marli.ctasca@gmail.com

${ }^{2}$ Doutora em letras, professora da Universidade de Caxias do Sul (UCS), Caxias do Sul, RS, Brasil. E-mail: ramos.fb@gmail.com
} 
partir de ilustrações (Camargo, 2000). Olavo Bilac, no início do século XX, é o escritor mais difundido entre o público mirim, sendo que Poesias infantis (primeira edição em 1904) teve 27 reedições até 1961 (Camargo, 2000). Bilac explora recursos poéticos, em especial a musicalidade; no entanto, conserva a vinculação com a escola, seja por meio da temática que retoma datas cívicas, seja por meio da exaltação de comportamentos adequados à criança cortês e educada. Nuances da voz infantil, aliadas a recursos poéticos, surgem em 1943, com O menino poeta, de Henriqueta Lisboa. O texto inicia o processo de ruptura com a cultura escolar e sugere poesia infantil livre de temas escolares. Mais adiante, respeitando o poético e oscilando entre acolher a voz infantil e assumir uma postura adulta, em 1964, é editado Ou isto ou aquilo, de Cecília Meireles. Em 1971, comparece no cenário brasileiro o livro $A$ arca de Noé, em que musicalidade, ludismo e perspectiva infantil se articulam para conversar com o leitor mirim. Na sequência, autores como Sérgio Capparelli, José Paulo Paes, entre outros, têm formado o acervo de poesia infantil contemporânea brasileira.

Atualmente, no país, uma diversidade de obras é produzida e classificada como poesia infantil brasileira, dificultando estudo que se proponha a dar conta do conjunto publicado. Assim, buscamos filtrar títulos a partir de obras que estariam alocadas em bibliotecas escolares brasileiras. Que obras poéticas são selecionadas para estarem à disposição dos estudantes brasileiros? Que concepções de poético essas obras veiculam? A delimitação da abrangência da investigação nos remete a acervos constituídos pelo Programa Nacional Biblioteca da Escola (PNBE), criado em 1997, pelo Governo Federal. O programa integra o Plano Nacional do Livro e Leitura e tem passado por redirecionamentos. Desde 2004, as bibliotecas escolares têm acolhido os livros, uma vez que se estabeleceu o propósito de valorizar esses espaços como promotores da universalização do acesso a acervos e ao conhecimento que eles abrigam.

Entendendo que a interação com o texto literário propicia a convivência com a diversidade de representações sobre a condição humana, as políticas públicas de leitura têm perseguido o objetivo de tornar a leitura uma realidade para todas as crianças, e garantir que essas crianças se tornem leitores para a vida toda. Em 2010, o PNBE selecionou 100 obras que, organizadas em quatro acervos, foram destinadas aos anos iniciais do ensino fundamental. Desse conjunto, 30 títulos consistem em 
obras poéticas - aqui compreendidas como obras organizadas a partir do gênero poema -, as quais são contempladas no quadro 1 a seguir.

QUADRO 1 - Obras poéticas selecionadas no PNBE 2010 - anos iniciais do ensino fundamental

\begin{tabular}{|c|c|c|c|}
\hline & $\mathbf{N}^{\mathbf{0}}$ & Obra & Autor/ilustrador \\
\hline \multirow{9}{*}{ Acervo 1} & 01 & Bichos & $\begin{array}{l}\text { Ronaldo Simões Coelho; } \\
\text { Angela Lago }\end{array}$ \\
\hline & 02 & Dia brinquedo & Fernando Paixão; Suppa \\
\hline & 03 & $\begin{array}{l}\text { Ervilina e o princês ou deu a } \\
\text { louca em Ervilina }\end{array}$ & Sylvia Orthof; Laura Castilhos \\
\hline & 04 & Fardo de carinho & Roseana Murray; Elvira Vigna \\
\hline & 05 & Feita de pano & $\begin{array}{l}\text { Valeria Belém; Adriana } \\
\text { Mendonça }\end{array}$ \\
\hline & 06 & No risco do caracol & $\begin{array}{l}\text { Maria Valéria Rezende; } \\
\text { Marlette Menezes }\end{array}$ \\
\hline & 07 & $\begin{array}{l}\text { O caso da lagarta que tomou chá } \\
\text { de sumiço }\end{array}$ & $\begin{array}{l}\text { Milton Celio de Oliveira Filho; } \\
\text { André Neves }\end{array}$ \\
\hline & 08 & Poemas da Iara & $\begin{array}{l}\text { Eucanaã Ferraz; Andrés } \\
\text { Sandoval }\end{array}$ \\
\hline & 09 & Só meu & Mario Quintana; Orlando \\
\hline \multirow{6}{*}{ Acervo 2} & 10 & $\begin{array}{l}\text { Circo mágico: poemas circenses } \\
\text { para gente pequena, média e } \\
\text { grande }\end{array}$ & $\begin{array}{l}\text { Alexandre Brito; Eduardo } \\
\text { Vieira da Cunha }\end{array}$ \\
\hline & 11 & Lé com cré & José Paulo Paes; Alcy \\
\hline & 12 & Lua no brejo com novas trovas & Elias José; Graça Lima \\
\hline & 13 & Poemas para assombrar & Carla Caruso \\
\hline & 14 & Rimas da floresta & José Santos; Laurabeatriz \\
\hline & 15 & $\begin{array}{l}\text { Trava-língua quebra-queixo } \\
\text { rema-rema remelexo }\end{array}$ & Almir Correia; Cláudia Ramos \\
\hline \multirow{3}{*}{ Acervo 3} & 16 & A arca de Noé & $\begin{array}{l}\text { Vinícius de Moraes; Nelson } \\
\text { Cruz }\end{array}$ \\
\hline & 17 & A cor de cada um & $\begin{array}{l}\text { Carlos Drummond de } \\
\text { Andrade }\end{array}$ \\
\hline & 18 & Berimbau e outros poemas & Manuel Bandeira; Graça Lima \\
\hline
\end{tabular}




\begin{tabular}{|l|l|l|l|}
\hline & $\mathbf{N}^{\mathbf{0}}$ & \multicolumn{1}{|c|}{ Obra } & \multicolumn{1}{c|}{ Autor/ilustrador } \\
\hline \multirow{5}{*}{} & 19 & Bicho que te quero livre & Elias José; Ana Raquel \\
\cline { 2 - 4 } & 20 & Boi da cara preta & Sergio Caparelli; Caulos \\
\cline { 2 - 4 } & 21 & Brincriar & Dilan Camargo; Joãocaré \\
\cline { 2 - 4 } & 22 & O fazedor de amanhecer & Manoel de Barros; Ziraldo \\
\hline \multirow{5}{*}{23} & Anacleto & $\begin{array}{l}\text { Bartolomeu Campos de } \\
\text { Queirós }\end{array}$ \\
\cline { 2 - 5 } & 24 & As meninas e o poeta & Manuel Bandeira, Graça Lima \\
\cline { 2 - 5 } & 25 & Conversa de passarinhos & $\begin{array}{l}\text { Alice Ruiz S.; Maria Valéria } \\
\text { Rezende; Fê }\end{array}$ \\
\cline { 2 - 5 } & 26 & $\begin{array}{l}\text { Duelo danado de Dandão e Dedé: } \\
\text { cantoria em trava-línguas }\end{array}$ & $\begin{array}{l}\text { Lenice Gomes e Arlene } \\
\text { Holanda; Andrea Ebert }\end{array}$ \\
\cline { 2 - 5 } & 27 & E um rinoceronte dobrado & $\begin{array}{l}\text { Hermes Bernardi Júnior, Guto } \\
\text { Lins }\end{array}$ \\
\cline { 2 - 5 } & 28 & Japonesinhos & Lalau; Laurabeatriz \\
\cline { 2 - 4 } & 29 & Ou isto ou aquilo & Cecília Meireles \\
\cline { 2 - 4 } & 30 & Se um dia eu for embora & Anna Göbel \\
\hline
\end{tabular}

Elaboração própria.

Fonte: dados da pesquisa.

A riqueza do conjunto compreende obras bem recentes ao lado de produções originalmente escritas para adultos e redirecionadas ao público infantil. Também se veem produções compostas por vários textos poéticos, ligados entre si pela proposta temática, ao lado de livros constituídos de um único poema. Veem-se obras em que são tematizados os animais e elementos da natureza, ao lado de outras em que brinquedos e brincadeiras se sobressaem, ou ainda, que trazem aspectos da subjetividade infantil. Apesar da diversidade de temas e modos de organização das obras, o conjunto ganha coesão no que se refere ao tom lúdico que predomina tanto na proposição de recursos sonoros quanto no tratamento das temáticas eleitas. Evidencia-se, pois, a preocupação com o acolhimento ao leitor contemporâneo, privilegiando seus interesses e modos de apreensão do mundo. Ao mesmo tempo, demarca-se um distanciamento em relação às leituras escolarizadas, tradicionalmente submetidas aos currículos, e uma consolidação da intencionalidade artística ensejada pelas obras, em seu diálogo com os interlocutores infantis. 
Em vista disso, como se delineia o leitor esperado pelos textos e que ações lhe são demandadas na leitura? As propostas dirigem-se a um leitor que teve experiências com o poético do mundo e já está familiarizado com a poesia, ainda que oral, em cantigas, parlendas, trovas e quadrinhas. Os materiais indicam ao leitor que a poesia não é um gênero simples ou previsível, pois é muito mais que um agrupamento de palavras que rimam, como frequentemente se crê. Nesse sentido, a preocupação com os sons alia-se à proposição inovadora de ideias, sentimentos e sensações para construir a poeticidade do texto. O leitor pressuposto, nessa proposta de poesia, é curioso, mobiliza seus saberes prévios, é capaz de realizar inferências e sensibilizar-se. Como letrado no gênero, ainda que em níveis elementares, é capaz de deleitar-se, entregar-se à leitura poética e à sua função social, percebendo a arquitetura complexa que torna possível, ao arranjo de palavras chamado poema, apreender a poesia.

Observa-se que o acervo possibilita a construção de um percurso na apropriação do poético, partindo da ênfase à sonoridade, passando por um nível intermediário, para enfocar, na sequência, a exploração imagética, considerando, ainda, a visualidade na disposição das palavras no espaço da página. Com essa organização e diversidade, o conjunto se oferece à trajetória de aprendizagem poética do leitor, propiciando a complexificação progressiva de suas relações com a poesia.

Para melhor analisar a constituição do poético no acervo, realizou-se uma seleção que excetuou as antologias, as obras constituídas de um único poema, bem como aquelas originalmente escritas para adultos e reendereçadas às crianças. $\mathrm{O}$ conjunto de títulos resultante foi então mapeado segundo seu traço poético mais evidente, delineando-se níveis progressivos de complexidade na constituição do poético. Estamos cientes, no entanto, que a organização das produções segundo tais níveis é, em certa medida, arbitrária e redutora, pois uma mesma obra apresenta poemas que contemplam níveis distintos. Ou isto ou aquilo (Meireles, 2002), por exemplo, enfatiza os jogos sonoros em poemas como "Jogo de bola" (p. 17), já o caráter imagético é sublinhado em outros, como "O último andar" (p. 35), enquanto outros mesclam as duas propostas com igual intensidade. As obras que se valem da intervenção da visualidade na constituição poética, por sua vez, o fazem apenas em alguns dos poemas, engajando-se, pois, igualmente, em outros níveis. O quadro 2 representa, portanto, uma composição possível, construída para fins didáticos, visando à 
escolarização da literatura, por meio da organização de projeto de leitura poética, aplicado a alunos dos anos iniciais do Ensino Fundamental. ${ }^{3}$

QUADRO 2 - Agrupamento de obras do PNBE 2010 segundo nível poético mais evidente

\begin{tabular}{|c|c|}
\hline Níveis de apropriação poética & Obras \\
\hline \multirow{2}{*}{$\begin{array}{l}\text { Musicalidade: presença de } \\
\text { rimas, assonâncias e } \\
\text { aliterações; evidência rítmica. }\end{array}$} & Boi da cara preta (Sérgio Caparelli, 2010) \\
\hline & $\begin{array}{l}\text { Trava-língua Quebra-queixo Rema-Rema Remelexo } \\
\text { (Almir Correia, 2008) }\end{array}$ \\
\hline \multirow{5}{*}{$\begin{array}{l}\text { Intermediário: presença da } \\
\text { musicalidade e do aspecto } \\
\text { imagético. }\end{array}$} & A arca de Noé (Vinicius de Moraes, 2004) \\
\hline & Bicho que te quero livre (Elias José, 2002) \\
\hline & Brincriar (Dilan Camargo, 2007) \\
\hline & Lua no brejo (Elias José, 2007) \\
\hline & Ou isto ou aquilo (Cecília Meireles, 2002) \\
\hline \multirow{8}{*}{$\begin{array}{l}\text { Imagético: presença de } \\
\text { metáforas/imagens verbais. }\end{array}$} & Circo mágico (Alexandre Brito, 2007) \\
\hline & $\begin{array}{l}\text { Conversa de passarinhos (Alice Ruiz S.; Maria } \\
\text { Valéria Rezende, 2008) }\end{array}$ \\
\hline & Fardo de carinho (Roseana Murray, 2009) \\
\hline & Japonesinhos (Lalau, 2008) \\
\hline & Lé com Cré (José Paulo Paes, 2009) \\
\hline & Poemas da Iara (Eucanaã Ferraz, 2008) \\
\hline & Poemas para assombrar (Carla Caruso, 2009) \\
\hline & Rimas da floresta (José Santos, 2007) \\
\hline \multirow{2}{*}{$\begin{array}{l}\text { Intervenção da visualidade: } \\
\text { disposição significante do texto } \\
\text { verbal no espaço. }\end{array}$} & Bichos (Ronaldo Simões Coelho, 2009) \\
\hline & Dia brinquedo (Fernando Paixão, 2009) \\
\hline
\end{tabular}

Elaboração própria.

Fonte: dados da pesquisa.

${ }^{3}$ A vivência da leitura de poesia das obras indicadas no quadro 2 foi parte da investigação experimental com estudantes do ensino fundamental, cujos resultados encontram-se em Marangoni (2015). 
A seguir, apresenta-se a leitura de um poema de cada nível, analisando-o segundo a peculiaridade poética que mais intensamente se oferece à participação do leitor. Com esse movimento, busca-se explicitar e exemplificar, ao mesmo tempo: i) peculiaridades da poesia infantil brasileira contemporânea; e ii) a trajetória de aprendizagem do poético viabilizada pelo acervo do PNBE 2010. Pretende-se, desse modo, evidenciar, sistemática e intencionalmente, a apropriação dos recursos poéticos em jogo na leitura de cada texto.

\section{Poesia para dizer e cantar}

O poema "A estrada e o cavalinho", de Sérgio Caparelli (2010, p. 30), aqui enfocado salienta a face sonora das palavras, caracterizando-se pela proposta rítmica, pelos jogos de palavras e pelas combinações de sons.

O cavalinho na estrada pacatá, pacatá,

com sua sombra mais atrás

pacatá, pacatá.

Para ao lado de um riacho, pacatá, pacatá,

e se vê no espelho d'água,

pacatá, pacatá.

Que água limpa e fresca, pacatá, pacatá, corre aqui, corre acolá, pacatá, pacatá, e uma sombra tão boa pacatá, pacatá, não vi noutro lugar, pacatá, pacatá, mas a estrada já me chama pacatá, pacatá, sempre está a me chamar, pacatá, pacatá.

O cavalinho volta à estrada pacatá, pacatá, com sua sombra mais atrás, pacatá, pacatá. 
A obra no interior da qual cavalga esse cavalinho intitula-se Boi da cara preta, que apresenta ilustrações de Caulos e, como o título sugere, volta-se ao aproveitamento do material folclórico, sejam parlendas, trava-línguas ou canções de ninar.

O poema "A estrada e o cavalinho" mimetiza o galope do cavalo em seu trajeto, pela repetição do som das patas - "pacatá, pacatá" - a cada verso. As duas primeiras estrofes, assim como a quarta, apresentam quatro versos e denotam ações do cavalinho em seu percurso. Já a terceira estrofe, de 12 versos, exprime o discurso do cavalinho, bem como suas reflexões, em discurso direto. Há, portanto, duas vozes no texto: a primeira que se ouve é a de um espectador que relata o andar do cavalinho "na estrada", "com sua sombra mais atrás", e que, a certa altura do percurso, "para ao lado de um riacho/e se vê no espelho d'água"; já por meio da segunda voz exprime-se o próprio cavalinho, que se admira do frescor da água e goza da boa sombra para, logo em seguida, atender ao apelo da estrada, voltando a percorrê-la.

Ao longo dos versos, o /a/ aberto é recorrente, não apenas na onomatopeia do galope, mas na seleção vocabular. É o que se vê, por exemplo, nas duas primeiras estrofes, em que comparecem os verbetes: "cavalinho", "estrada", sombra", "atrás", "para", "lado", "riacho", "água”. Embora quase não haja rimas consoantes, a reiteração desse som em oxítonas que finalizam versos (por exemplo, em "atrás", "acolá"), contribui para dar sonoridade ao poema, ecoando o "pacatá". O /a/ sugere justamente abertura de horizontes, expansão, independência e ousadia, para o que converge a imagem de um cavalo correndo sem rédeas.

$\mathrm{O}$ som das patas, repetido a cada verso, impõe ritmo à leitura, que contribui para presentificar a imagem do cavalo galopando. As sílabas poéticas dos versos, em sua maioria de seis e sete, também cooperam com a instalação do ritmo, de tal modo que o poema pode ser cadenciado. O que diz o ritmo, dizem também as palavras: o cavalinho não pode ficar à sombra junto à água fresca, pois a estrada o chama com urgência para retomar sua viagem. A fala do animal traduz sua admiração diante do que encontrou: a água limpa e fresca, que corre aqui e acolá, e uma sombra boa como em nenhum outro lugar.

A exclamação do cavalinho é seguida de uma conjunção adversativa, o "mas", que assinala a saída do descanso para a atividade e do devaneio para a realidade, com o retorno à estrada. Assim como corre o rio, o cavalinho deve correr, e sente a estrada a chamá-lo. Não é para a sombra 
e a água fresca que ele é feito, senão para a estrada. O cavalinho não está a passeio e sua disposição diante do caminho contribui para a ideia de que algo está em jogo. Esse aspecto traduz a busca incessante do cavalinho, que também se assemelha ao percurso humano no mundo.

O vocábulo "pacatá", com consoantes oclusivas seguidas da vogal aberta, indica a alternância entre a continuidade da estrada e a parada do cavalinho. A repetição do "pacatá, pacatá", nesse sentido, sugere a intercalação entre o movimento e a quietude, o deslocamento externo e a contemplação, o olhar para fora (estrada) e o olhar para dentro (reflexo na água). A viagem do cavalinho é exigente e passa pelo autoconhecimento, associado à mirada no espelho d'água. A liberdade é um dever a ser cumprido. Esse aspecto relativiza a ideia de escolha, comumente associada à estrada.

\section{Poesia para imaginar}

A exploração dos sons da língua aliada à construção imagética é priorizada neste tópico, intermediando o acesso a recursos mais complexos da poeticidade. O poema contemplado nesta seção é "Telefone sem fio", de Dilan Camargo (2007), que integra a obra Brincriar. Ilustrado por Joãocaré, Brincriar é uma proposta organizada a partir da exploração de brinquedos, canções e brincadeiras populares (como "Ovo choco", "Cabra-cega", "Esconde-esconde", "Pau no gato?") e personagens familiares ao universo infantil (como "A bruxa Carocha", "A fada Mafalda", "Embalos no colo da mãe" e "Pai"). Como o título da publicação sugere, o tom lúdico permeia os poemas, propostos como espaço para brincar, rir e criar.

O segundo poema da obra intitula-se "Telefone sem fio" (p. 8-9) e retoma a brincadeira folclórica de mesmo nome, na qual, o desafio é fazer chegar à última pessoa da roda o que foi dito pela primeira, passando a mensagem de ouvido em ouvido. Os equívocos e confusões que acontecem na transmissão das palavras geram imagens ilógicas e engraçadas, suscitando o prazer na brincadeira, como percebemos no texto:

O primeiro disse:

"excelente".

O último entendeu:

"isso é leite".

O primeiro disse: 


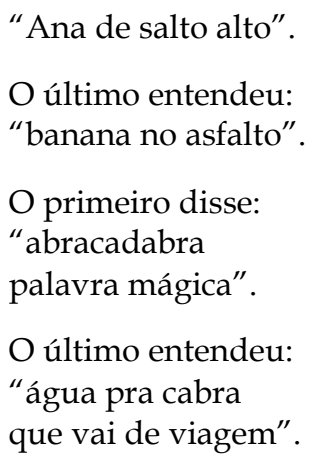

Como na brincadeira, o poema propõe imagens inesperadas a partir de equivalências sonoras entre o que "o primeiro disse" e o que "o último entendeu". Assim, "excelente", tornou-se "isso é leite"; "Ana de salto alto" virou "banana no asfalto"; "abracadabra/palavra mágica" resultou em "água pra cabra/que vai de viagem". Em seis dísticos, sugere-se que a brincadeira aconteceu três vezes, intercalando-se a fala inicial e o modo como ela chegou ao fim da brincadeira. Cabe ao leitor a possibilidade de imaginar as falas intermediárias, já que fica implícito que as transformações na mensagem costumam acontecer aos poucos, com os equívocos de vários partícipes em meio ao jogo.

A sequência de "primeiros" e "últimos" que se desenha ao longo dos versos lhes confere narratividade, sugerindo o desenvolvimento do episódio do jogo em seu início, reinícios e fim. A descontinuidade entre as imagens oriundas das falas primeiras e últimas é encadeada pelo verso que inicia cada estrofe, o qual introduz os dizeres dos sujeitos que brincam, entre aspas, ligando-os ao todo da brincadeira. Os elos sonoros estabelecem vínculos coesivos no texto, contrapondo-se à desconexão do sentido que caracteriza a relação das falas entre si.

Além da rima, os versos propõem correspondências internamente às palavras, de modo que em "excelente", o fragmento / exce/ leva a "isso é" e o fragmento /lente/ torna-se "leite". O título "Telefone sem fio" sugere uma conversa "sem pé nem cabeça", cuja ligação entre a fala de um e de outro acontece pelo som, ao contrário do que se dá nas conversas telefônicas, que buscam a objetividade e a clareza na linguagem. $\mathrm{O}$ jogo seria bem-sucedido quando a fala do último corresponde com exatidão à fala do primeiro. Mas os enganos são festejados com riso, pela alegre surpresa que advém das possibilidades 
da língua, as quais criam realidades novas "sem querer" ou quase "ao acaso", por meio de sutis substituições sonoras.

\section{Poesia para investigar}

Poemas são enigmas que pedem uma resposta. Nesta seção, privilegiase um haikai que, com sua organização sintética e lacunar, mobiliza o leitor a completar a fotografia desenhada, formulando os elos não ditos entre os elementos. Diferentemente dos poemas anteriores, em que o aspecto lúdico está na "pele" dos poemas, no seu trabalho sonoro, instigando a atuação do corpo, aqui o ludismo está mais escondido, pois trata de "desfocar" o olhar sobre o real, produzindo nova leitura deste. A análise ocupa-se do poema "Mão de menino", assim identificado pelo verso inicial, da obra de Alice Ruiz S. e Valéria Rezende (2008).

Conversa de passarinhos (Ruiz S. e Rezende, 2008) apresenta, já na capa, a proposta de veicular "haikais para crianças de todas as idades". A obra é inteiramente composta de breves textos poéticos acerca de variadas espécies de aves. Antes de comparecerem os poemas, uma das autoras, Alice Ruiz S. explica aos leitores "o que é haikai", trazendo alguns dados históricos e especificidades dessa forma poética, os quais esclarecem, por exemplo, que o texto se faz com três versos e, no máximo, 17 sílabas, e que muitos o definem como uma fotografia sem palavras.

Quando o leitor abre o livro, é isso o que encontra: um álbum de imagens, construído com palavras e sensibilidade. Como é peculiar nessa proposta poética, os poemas primam por captar sinteticamente algum aspecto ou elemento da realidade em sua essência, pouco recorrendo a adjetivações e comparações. Ao longo do título, intercalam-se os haikais de ambas as autoras, identificadas pelas iniciais do seu nome ao fim do texto. A cada página, comparecem dois poemas, o primeiro de Alice Ruiz S. e o segundo de Maria Valéria Rezende, que "fotografam" com palavras exatas um momento de ave. Por sua característica sintética, os textos são lacunares e sintaticamente econômicos. Os poemas não apresentam título, sinais de pontuação ou letras maiúsculas, conferindo aos versos um aspecto de nudez que cuida do essencial e elege o absolutamente necessário para ser dito.

mão de menino

sobe uma pedra nos ares

cai passarinho (MV) 
O haikai acima é de autoria de Maria Valéria e encontra-se na parte inferior da página 45. O poema apresenta uma sequência de três elementos, sugerindo sucessão de ação e consequências. O quadro que os versos desenham revela um passarinho que cai, em razão da pedra atirada por um menino.

Enquanto o primeiro e o terceiro versos apresentam quatro sílabas poéticas, o segundo organiza-se em sete sílabas. Essa organização emoldura o verso central, em que a pedra sobe aos ares, antecedendoo com o elemento que deflagra a ação ("mão de menino") e fechando com a sua consequência ("cai passarinho"). Também do ponto de vista sonoro, o primeiro e o terceiro verso convergem com o estabelecimento da rima toante entre os seres que se contrapõem "menino" e "passarinho" - e com palavras monossilábicas a iniciar os versos, respectivamente "mão" e "cai".

No interior do segundo verso, as palavras lexicais são dissílabas e paroxítonas, e possuem uma vogal aberta na sílaba tônica, a saber: "sobe", "pedra", "ares", articulação que engendra o movimento ascendente da pedra, opondo-se ao passarinho que cai, no verso seguinte. Comparecem também no poema várias ocorrências de consoante nasal em "mão", "menino", "uma", "nos", "passarinho", aspecto que confere musicalidade aos versos.

A imagem que a cena compõe constrói-se a partir da oposição entre "subir" e "cair", mediada pela mão do menino. A mão representa o fazer intencional e calculado, pois é capaz de movimentação ágil, direção precisa e força avaliada. A pedra pertence ao chão, os ares são espaço do passarinho. Quando o que é do chão atinge o que vive no ar, completa-se a inversão, com a queda da ave ao solo.

"Mão de menino" oferece-se ao leitor como um enigma, para que explicite o que ocorreu entre um verso e outro. $\mathrm{O}$ quadro proposto pelo poema sugere uma cena, cujo desenrolar não está dito. Essa peculiaridade da forma poética insta o leitor a estabelecer relações de causa e consequência e realizar a inferência que dá sentido aos versos. Como um detetive, o leitor precisa "ler" atentamente as pistas dispostas no espaço do poema, para desvendar a articulação entre as peças do quebra-cabeça, reconstruindo seu caráter de narratividade. 


\section{Poesia para ler e ver}

Outra instância da poeticidade pode ser construída pela visualidade. Como afirma o poeta Carlos Drummond de Andrade (2000, p. 9), "as palavras não nascem amarradas, / elas saltam, se beijam, se dissolvem, / no céu livre por vezes um desenho". O texto aqui enfocado explora o espaço da página e a disposição diferenciada das palavras e letras em sua superfície para constituir sentidos, por meio de imagens, desenhos. Tratase de "Dois trapezistas no ar" (figura 1), de Fernando Paixão (2009).

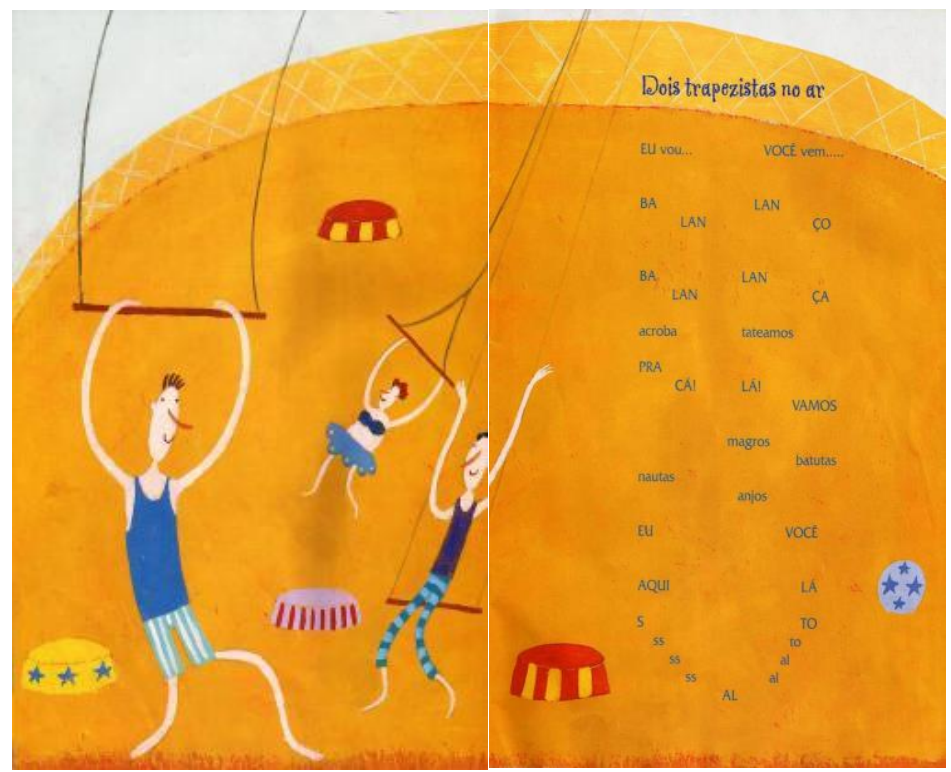

FIGURA 1 - Poema "Dois trapezistas no ar".

Fonte: Fernando Paixão (2009, p. 9-10).

Pertencente à obra Dia brinquedo, o poema "Dois trapezistas no ar" (Paixão, 2009, p. 10) mantém a proposta lúdica, agora, porém, executada distintamente. Enquanto nos poemas anteriores predominava a musicalidade e a imagética, bem como sua combinação, aqui o recurso mais evidente é a distribuição diferenciada das palavras e sílabas do poema pela página para a construção poética. Localizando-se ora mais à direita, ora mais à esquerda, os fragmentos criam simetria entre os lados 
opostos, que constrói o movimento dos dois artistas ao trapézio, de um lado a outro do picadeiro e ao centro. A disposição na página sugere dois corpos que se encontram e trocam de lugar a partir do centro.

Letras maiúsculas, minúsculas, pontos exclamativos, reticências e espaços vazios contribuem para recriar a movimentação coreografada e emocionante dos trapezistas, pressupondo balanço e embalo, salto e retomada, além de sugerir ações individuais e em conjunto. Se, de um lado, "EU vou...", de outro lado, "VOCÊ vem...", se eu "BA-LANLAN-ÇO”, você “BA-LAN-LAN-ÇA", um “CÁ!", outro "LÁ!”, e assim por diante. Contudo, em alguns pontos do espetáculo, encontram-se os acrobatas: ambos tateiam e vão, ambos são "magros", "nautas", "batutas", "anjos".

A escassez de elos entre as palavras e sílabas exige do leitor que estabeleça a conectabilidade. $\mathrm{O}$ apelo à visualidade, porém, dá concretude ao texto, aproximando do receptor a experiência corporal do trapezista. O fato de as palavras e letras estarem soltas na página, transgredindo a ideia de linha, recupera o deslocamento aéreo dos artistas, que estão distantes do chão e flutuam em várias direções.

De modo não linear, os artistas movem-se aos saltos, de um lado a outro, para cima e para baixo, em cursos ascendentes e descendentes, ora sincopando a ação, propondo, em vez de "acrobatas tateamos", "acroba tateamos", e ora dissociando o movimento e prolongando-o, até alcançar o outro trapézio, como em "S ss ss ss AL al al to TO". Assim, para ler, os olhos do leitor realizam os movimentos dos trapezistas. Suas acrobacias pela página também se assemelham à ação ao trapézio, pela necessidade de se equilibrar em uma proposta nova de leitura, na qual ele deve saltar, de modo ousado, agarrando-se aos trapézios das palavras, para construir o sentido.

Na escolha das palavras e expressões, alguns paralelismos sintáticos assinalam a duplicidade dos movimentos. Os pronomes "eu" e "você", assim como os advérbios "cá" e "lá", "aqui" e "lá", marcam a posição espacialmente oposta dos artistas e, como dêiticos, denotam a mobilidade dos sujeitos, como referentes que trocam de lugar. Os vocábulos "magros" e "batutas" caracterizam os artistas física e subjetivamente, enquanto que "nautas" e "anjos" os aproximam de figuras instigantes, respectivamente, exploradores corajosos do espaço e habitantes benfazejos dos céus e hábeis no voo. 
A profusão do sibilante /s/ sugere a continuidade do movimento: de um braço a outro, de um trapézio a outro, de um trapezista a outro. Além disso, esse som é a marca do plural na nossa língua, de modo que a sua reiteração sublinha a característica dual e cooperativa das ações dos artistas ao trapézio. Assim também é a atuação do leitor junto ao texto, já que, no evento da leitura, ambos cooperam mutuamente para a concretização dos sentidos, colocando em jogo seus horizontes e limites.

\section{Considerações finais}

Ao investir na leitura da poesia, fica-se mais perto de garantir um espaço onde a infância possa brincar com as palavras e suas possibilidades, e de viabilizar que o ser em formação possa encontrar na escrita o poético que lê em seu mundo e em sua vida. Este estudo deteve-se, primeiramente, sobre o conjunto das obras poéticas destinadas às bibliotecas escolares pelo PNBE 2010, buscando lançar olhar de sobrevoo ao acervo. Em seguida, dedicamo-nos às especificidades que dão ao texto o estatuto de poético, verificando sua concretização enquanto "jogo" que provoca o leitor, seja no nível do significante ou no do significado, seja em ambos.

A partir do corpus analisado, é possível perceber que o texto poético feito para a criança, integrante dessa política pública, tem se caracterizado pela proposição de variados modos de recepção e atuação do ser infantil, pautada do ludismo: há poesia para a criança dizer e cantar, imaginar, investigar, ler e ver, muitas vezes combinando possibilidades no mesmo texto. Se o conhecimento primordial do ser infantil não resulta dos livros, mas "de pegar de apalpar de ouvir e de outros sentidos" - como indica a epígrafe de Manoel de Barros no início deste artigo -, o poema escrito melhor conversa com a infância quando consegue, atravessando a escrita, provocar sensações e percepções, a exemplo do andar do cavalo (como em "A estrada e o cavalinho", de Sérgio Caparelli), o dos acrobatas em ação (como em "Dois trapezistas do ar", de Fernando Paixão). O diálogo entre o texto poético escrito e a criança tende a ser bem-sucedido quando as palavras se juntam "uma na outra por amor / e não por sintaxe" (Barros, 2010, p. 11), isto é, quando se combinam de modo inusitado (a exemplo do que predomina no poema "Telefone sem fio", de Dilan Camargo) e quando a objetividade racional da construção "casa-se" com a sensibilidade da 
experiência evocada subjetivamente (como em "Mão de menino", de Maria Valéria Rezende).

Os poemas eleitos para este estudo denotam a pluralidade de propostas poéticas que caracteriza o acervo do PNBE. Assim como na Grécia Antiga a poesia nasceu para ser dita e cantada, a criança refaz o percurso da humanidade, iniciando a apropriação do poético pela sonoridade dos versos. Por isso, o itinerário proposto neste estudo partiu do "arpejo", do "canto", do "gorjeio das palavras", isto é, da musicalidade, o nível mais concreto e familiar de captura do texto poético. Depois de um nível intermediário, enfocou-se a instância imagética, que envolveu relações mais complexas entre os dados textuais. Por fim, a proposta compreendeu a visualidade da página, pela disposição diferenciada do texto verbal, como outra dimensão possível para a constituição do poético.

Em sintonia com os modos contemporâneos de ler, a leitura poética a partir dos títulos selecionados pela edição do PNBE 2010 prioriza recursos lúdicos que dialogam interativamente com a infância, distanciando-se da tradição escolar e propondo a poesia como brinquedo linguístico. A exploração dos sons da língua, o aproveitamento do material folclórico, a tensão entre o familiar e o desconhecido, a utilização da espacialidade da página e o emprego do humor são alguns dos recursos que atualizam a poesia destinada à criança e demandam do leitor atuação na concretização do texto.

A proposta do acervo é dialogar com a criança, pois os poemas constroem sua poeticidade solidarizando-se com o olhar infantil, seja buscando a concretude dos sons, seja traduzindo em imagens as abstrações. Tal aspecto demonstra, por um lado, a preocupação em contemplar leitores em diferentes níveis de letramento poético. Por outro lado, o acervo delineia percurso possível de aprendizagem do poético, privilegiando poemas que pressupõem uma atuação diferenciada do interlocutor, viabilizando o "acompanhamento" progressivo desse leitor na interação com a poeticidade. Nesse sentido, evidencia-se que o programa atenta para a meta de formação do leitor do texto poético, uma vez que, no acervo, encontra-se desde o poema essencialmente musical até aquele quase puramente imagético.

Ao favorecer a progressiva instrumentalização do leitor para lidar com o poético e tornar-se letrado em poesia, a edição do PNBE abordada aqui problematiza o fazer educativo, em esforço consciente 
na direção de melhor compreender o poético e sua construção, no território da infância escolarizada, lá onde o conhecimento geralmente vem "de estudar em livros". O estudo demonstra que os textos poéticos escritos para a infância dos nossos dias buscam conjugar o amadurecimento do sujeito infantil com seu "saber primordial", que vem dos sentidos e do sentir. O canto e a oralidade, a imaginação, a investigação e a visualidade tendem a ser convocados para concretizar a natureza ao mesmo tempo interativa e contemplativa da leitura poética, tendo em vista o leitor em formação.

\section{Referências}

ANDRADE, Carlos Drummond de (2000). A rosa do povo. 21. ed. Rio de Janeiro: Record.

BARROS, Manoel de (2010). Menino do mato. São Paulo: Leya.

BRASIL. Fundo Nacional de Desenvolvimento da Educação (2009). Programa Nacional Biblioteca da Escola - PNBE. Edital PNBE 2010. Brasília. Disponível em: https://goo.gl/gysEzQ. Acesso em: 23/07/2014.

BRASIL. Ministério da Cultura; Ministério da Educação (2006). Plano Nacional do Livro e Leitura - PNLL. Brasília. Disponível em: https://goo.gl/9DGDqx. Acesso em: 10 dez. 2016.

BRASIL. Decreto ${ }^{\circ} 7.084$, de 27 de janeiro de 2010. Dispõe sobre os programas de material didático e dá outras providências. Diário Oficial da União, Poder Executivo, Brasília, n. 18-A, seção 1, p. 3-5. Disponível em: https://goo.gl/AMWj95. Acesso em: 10 dez. 2016.

CAMARGO, Luis (2000). A poesia infantil no Brasil. Palestra apresentada no Instituto Latino-americano da Universidade de Estocolmo, em outubro de 1999. Blocos - Portal de Literatura e Cultura, Maricá. On-line. Disponível em: https://goo.gl/6Oaa0q. Acesso em: 10 dez. 2016.

Freire, Paulo (1988). A importância do ato de ler: em três artigos que se completam. 22. ed. São Paulo: Cortez.

MARANGONI, Marli C. T. (2015). Brincadências com a poesia infantil: um quintal para o letramento poético. 2015. 229 p. Tese (Doutorado em Letras) Universidade de Caxias do Sul e UniRitter, Caxias do Sul. Disponível em https://goo.gl/Q0XGiq. Acesso em: 10 dez. 2016. 
RAMOS, Flávia B.; MARANGONI, Marli C. T. (2016). Ecos da poesia no leitor mirim. Pro-Posições, Campinas, v. 27, n. 2, p.67-92, maio/ago. Disponível em: https://goo.gl/RxJwYj. Acesso em: 10 dez. 2016.

\section{Obras poéticas do PNBE 2010}

ANDRADE, Carlos Drummond de (2010). A cor de cada um. 13. ed. Rio de Janeiro: Civilização Brasileira.

BANDEIRA, Manuel (2006). Berimbau e outros poemas. Seleção de Elias José. Ilustrações de Graça Lima. 3. ed. Rio de Janeiro: Nova Fronteira.

BANDEIRA, Manuel (2009). As meninas e o poeta. Organização de Elias José. Ilustrações de Graça Lima. 2. ed. Rio de Janeiro: Lacerda.

BARROS, Manoel de (2009). O fazedor de amanhecer. Ilustrações de Ziraldo. São Paulo: Richmond Educação.

BERNARDI JÚNIOR, Hermes (2008). E um rinoceronte dobrado. Ilustrações de Guto Lins. Porto Alegre: Projeto.

BELÉM, Valéria (2009). Feita de pano. Ilustrações de Adriana Mendonça. São Paulo: IBEP Gráfica.

BRITO, Alexandre (2007). Circo mágico: poemas circenses para gente pequena, média e grande. Ilustrações de Eduardo Vieira da Cunha. Porto Alegre: Projeto.

CAMARGO, Dilan (2007). Brincriar. Ilustrações de Joãocaré. Porto Alegre: Projeto.

CAPARELLI, Sérgio (2010). Boi da cara preta. Ilustrações de Caulos. 36. ed. Porto Alegre: L\&PM.

CARUSO, Carla (2009). Poemas para assombrar. Ilustrações da autora. Cajamar, SP: Escala Integrada.

COELHO, Ronaldo Simões (2009). Bichos. Ilustrações de Angela-Lago. Belo Horizonte: Aletria.

CORREIA, Almir (2008). Trava-língua, quebra-queixo, rema-rema, remelexo. Ilustrações de Cláudia Ramos. São Paulo: Cortez.

FERRAZ, Eucanaã (2008). Poemas da Iara. Ilustrações de Andrés Sandoval. Rio de Janeiro: Língua Geral. 
GÖBEL, Anna (2008). Se um dia eu for embora. Ilustrações da autora. Belo Horizonte: Autêntica.

GOMES, Lenice; HOLANDA, Arlene (2009). Duelo danado de Dandão e Dedé: cantoria em trava-línguas. Ilustrações de Andrea Ebert. São Paulo: Elementar.

JOSÉ, Elias (2002). Bicho que te quero livre. Ilustrações de Ana Raquel. 2. ed. Coleção Girassol. São Paulo: Moderna.

JOSÉ, Elias (2007). Lua no brejo. Ilustrações de Graça Lima. Porto Alegre: Projeto.

LALAU. Japonesinhos (2008). Ilustrações de Laurabeatriz. São Paulo: Print House.

MEIRELES, Cecília (2002). Ou isto ou aquilo. Ilustrações de Thais Linhares. 6. ed. Rio de Janeiro: Nova Fronteira.

MORAES, Vinicius de (2004). A arca de Noé. Ilustrações de Nelson Cruz. São Paulo: Companhia das Letrinhas.

MURRAY, Roseana (2009). Fardo de carinho. Ilustrações de Elvira Vigna. 3. ed. Belo Horizonte, MG: Lê.

OLIVEIRA FILHO, Milton Célio de (2007). O caso da lagarta que tomou chá de sumiço. Ilustrações de André Neves. São Paulo: Brinque-Book.

ORTHOF, Sylvia (2009). Ervilina e o Princês: ou deu a louca em Ervilina. Ilustrações de Laura Castilhos. Porto Alegre: Projeto.

PAES, José Paulo (2009). Lé com cré. Ilustrações de Alcy. São Paulo: Abril.

PAIXÃO, Fernando (2009). Dia brinquedo. Ilustrações Suppa. São Paulo: Abril.

QUINTANA, Mário (2007). Só meu. Ilustrações de Orlando. São Paulo: Global.

QUEIRÓS, Bartolomeu Campos de (2008). Anacleto. Ilustrações de Júlia Bianchi. São Paulo: Larousse do Brasil.

REZENDE, Maria Valéria (2008). No risco do caracol. Ilustrações de Marlette Menezes. Belo Horizonte: Autêntica.

RUIZ S., Alice; REZENDE, Maria Valéria (2008). Conversa de passarinhos: haicais. Ilustrações de Fê. São Paulo: Iluminuras.

SANTOS, José (2007). Rimas da floresta: poesia para os animais ameaçados pelo homem. Ilustrações de Laurabeatriz. São Paulo: Peirópolis.

Recebido em fevereiro de 2016.

Aprovado em agosto de 2016. 


\title{
resumo/abstract/resumen
}

\section{Um estatuto para a poesia infantil contemporânea: reflexões a partir do PNBE: reflexões a partir do PNBE}

\author{
Marli Cristina Tasca Marangoni
}

Flávia Brocchetto Ramos

Ações governamentais de fomento à leitura, como o Programa Nacional Biblioteca da Escola, tendem a orientar o mercado editorial brasileiro, no sentido de ofertar obras que atendam às demandas de tal política e, consequentemente, contribuam para configurar um estatuto da literatura infantil e juvenil brasileira. Assim, para analisar peculiaridades da poesia infantil brasileira, foram selecionadas obras poéticas do acervo do PNBE 2010. Após apresentação dos títulos poéticos do acervo, foram analisados quatro poemas de quatro obras, a fim de discutir a composição do poético na poesia infantil brasileira selecionada pelo PNBE. O artigo discute o estatuto da poesia infantil brasileira na contemporaneidade, a partir de uma política governamental, e sinaliza que os textos poéticos tendem a convocar o leitor em formação a concretizar a natureza ao mesmo tempo interativa e contemplativa da poesia.

Palavras-chave: literatura infantil brasileira, poesia infantil contemporânea, Programa Nacional Biblioteca da Escola.

\section{A state for the contemporary children's poetry: reflections based on PNBE}

Marli Cristina Tasca Marangoni

Flávia Brocchetto Ramos

Government initiatives meant to promote reading, such as the National School Library Program (PNBE - Programa Nacional Biblioteca da Escola), influence the Brazilian publishing market, determining what book titles are offered to schools that meet the demands of such a policy and, consequently, contribute to the creation of a Brazilian children's and youth literary state. In order to analyze Brazilian children's poetry, this essay uses selected poetic works from the PNBE 2010 collection. Four poems from four different books were analyzed to discuss the poetic composition in Brazilian children's poetry selected by PNBE. The article analyzes the identity of Brazilian children's poetry in contemporary society, considering the government policy, and shows that the poetic texts tend to invite the young reader to substantiate the interactive and, at the same time, contemplative nature of poetry.

Keywords: Brazilian children's literature, contemporary children's poetry identity, Programa Nacional Biblioteca da Escola. 


\section{Un estado para la poesía infantil contemporánea: reflexiones desde PNBE}

Marli Cristina Tasca Marangoni

Flávia Brocchetto Ramos

Las acciones del gobierno para fomentar la lectura, como el Programa Nacional Biblioteca en la Escuela, tienden a orientar el mercado editorial brasileño, para ofrecer obras que cumplan con las exigencias de una política de este tipo y por lo tanto contribuir a establecer un estado de la literatura infantil y juvenil brasileña. Así, para analizar las peculiaridades de la poesía infantil brasileña, fueron seleccionadas las obras poéticas del acervo del PNBE 2010. Después de la presentación de los títulos poéticos de la colección, se analizaron cuatro poemas de cuatro obras con el fin de discutir la composición poética en la poesía infantil brasileña seleccionada por PNBE. El artículo analiza la situación de la poesía infantil brasileña en la sociedad contemporánea a partir de la política del gobierno, y constata que los textos poéticos tienden a convocar al lector en formación a concretizar la naturaleza al mismo tiempo interactiva y contemplativa de la poesía.

Palabras clave: literatura infantil brasileña, poesía infantil contemporânea, Programa Nacional Biblioteca da Escola 